\title{
MULTIFRACTAL ANALYSIS OF THE COMMON CROSSING TRACK-SIDE MEASUREMENTS
}

\author{
Mykola SYSYN ${ }^{1,{ }^{*}}$, Libor IZVOLT ${ }^{2}$, Olga NABOCHENKO ${ }^{3}$, Vitalii KOVALCHUK ${ }^{3}$, \\ Janka SESTAKOVA ${ }^{2}$, Andriy PENTSAK ${ }^{4}$ \\ ${ }^{1}$ Institute of Railway Systems and Public Transport, Technical University of Dresden, Germany. \\ ${ }^{2}$ Department of Railway Engineering and Track Management, Faculty of Civil Engineering University \\ of Zilina, Zilina, Slovakia. \\ ${ }^{3}$ Department of the Rolling Stock and Track, Lviv Branch of Dniprovsk National University of Railway \\ Transport, Lviv, Ukraine. \\ ${ }^{4}$ Department of Construction Industry, Lviv Polytechnic National University, Lviv, Ukraine. \\ corresponding author: sysyn@tu-dresden.de.
}

\begin{abstract}
The deterioration common crossing elements increase the need for the maintenance of crossings and significantly reduce the reliability, availability and safety of railway traffic. The present paper introduces the results of experimental investigation of common crossing monitoring while its deterioration during the lifecycle of crossing. The conventional methods of common crossing condition estimation with time-based features like maximal accelerations, etc. are low appropriate as statistically significant condition indicators. The proposed multifractal analysis enables to extract the significant features from acceleration measurements. The extracted features are fused together with information about the train velocities and longitudinal position of wheels impact with the Lasso regularisation and multivariate linear regression. A ranking of feature importance is done and the redundant features are identified. The developed condition indicator has good correlation to the crossing lifetime and is simple for interpretation.
\end{abstract}

\author{
Keywords: \\ Railway common crossing; \\ Track-side measurements; \\ Condition indicators; \\ Multifractal analysis; \\ Lasso regularisation.
}

\section{Introduction}

Railways transportation plays a central role in the strategies [1] of European sustainable transport system development and the energy transition concept of Germany other European countries [2]. The role cannot be assured without high performance of railway operation, reduction of maintenance costs, and improving the availability of railway transportation. The availability and reliability of railway transportation depend first on the performance of railway infrastructure. The maintenance costs of railway infrastructure consist of the costs for the track superstructure, signaling devices, catenary and engineering constructions maintenance. The main cost driver of maintenance costs is the track superstructure that shares up to half of the overall maintenance costs [3]. Thereby, almost $33 \%$ of the total maintenance costs of railway track are spent for the renewal and maintenance of switches and crossings (S\&C) [4]. Therefore, S\&C is one of the main cost drivers of track maintenance.

A railway $S \& C$ structure consists of the following main parts: switch rails, common crossing with guardrails and sleepers. A common crossing, due to high dynamic loading of wheels, has disproportionately short lifecycle. The common crossings assembled from steel R350 have 5 - 10 times lower than the lifecycle of the plain track $[5,6]$. Furthermore, the crossing lifecycle is usually finished with rail contact fatigue (RCF) damages. Contrary to other crossing failures like rail wear, ballast settlements etc., the RCF failures are developing not evenly over the lifecycle. Therefore, the RCF failures are difficult to detect recently and predict their development with ordinary scheduled inspections. For that reason, the unexpected RCF failures on common crossing rails can require the unplanned maintenance works with long-term traffic interruption. According to the approximate 
estimates [7], the $6 \%$ of unplanned S\&C faults in the railway network of the Netherlands, could cause $55 \%$ of train delays. Consequently, the S\&C is a significant factor influencing the availability of railway transportation.

The general reason of the high maintenance costs and at the same time, not satisfactory availability is the scheduled inspections. The conventional switch inspections are time-expensive and low automated, contrary to the plain track, where the inspection is carried out with high-effective measuring cars. Therefore, the way to improve the availability with more frequent scheduled inspections of crossings is inacceptable due to the explosion of already high inspection costs. The transition from the scheduled maintenance to the preventive or predictive maintenance with the concept of prognostics and health management (PHM), is increasingly taking place in the railway companies [8]. A growing number of national and international projects and publications confirm the interest of industry and researchers in the development of railway infrastructure PHM. The study [9] presents a wireless system for sleeper vibrations measurement, that is used to estimate sleeper deflection and the vertical track stiffness. A similar system [10] that is based on the sleeper acceleration measurements for S\&C, is tested on the German (DB) and Switzerland (SBB) Railways. The specialty of the system is long-term up 2 years autonomous monitoring of sleeper deflections. Russian railways $(\mathrm{RZhD})$ are testing the autonomous system stress and temperature control in continuous welded rails [11]. The system can detect the danger of track buckling of rail break and is integrated in the railway signaling system. Monitoring of railway ballast and sublayers on the highspeed railways of SNCF is provided on test sections with 127 sensors that includes accelerometers, anchored displacement sensors, temperature and humidity probes, and extensometers [12]. The distributed acoustic sensor technology, that is based on optical fiber real-time monitoring and positioning, is tested on heavy-haul railways of China Railways [13]. A Sensor Platform Sensor4PRI for monitoring of slab track is developed in the context of the FASTRACK [14] project and is tested on Spanish railways. The system is based on wireless sensor networks that include acceleration, inclination and distance sensors that send the measurement data to the receiver in the rolling stock. $A$ Vision Based Condition Monitoring Approach for S\&C is introduced in [15]. A 3D reconstruction of a crossing nose cracks with X-ray tomography is proposed within the project INTELLISWITCH [16].

The reviewed railway infrastructure monitoring methods have various work principle, provide diverse information types and amount of information. However, the sustained application of the monitoring method with railway companies depends also on the costs of the methods. The present paper deals with the portable monitoring system ESAH-M (Electronic Analysis System of Crossing Portable), that is used for common crossing monitoring on German railways DB [17]. Fig. 1, right shows the system ESAH-M that is installed for measurement on a common crossing.

The development of common crossing RCF (Fig.1, left) is accelerated over the lifetime and can be visually observed after about $75 \%$ of the lifecycle. Therefore it is difficult with conventional scheduled visual inspection recently detect and predict RCF damages. Contrary to the visual inspections and other monitoring methods that asses the RCF symptoms, the system ESAH-M is monitoring the RCF reasons. The growth of dynamic loading causing the damages can be detected much earlier before the first visual crack appears. The main advantage of the ESAH-M system before the stationary systems is that it is portable and therefore, can be used for monitoring of many crossings with one system. The system acquires, additionally to 3D accelerations, also the wheel impact position on the frog nose and train velocities that is the further technical advantage.

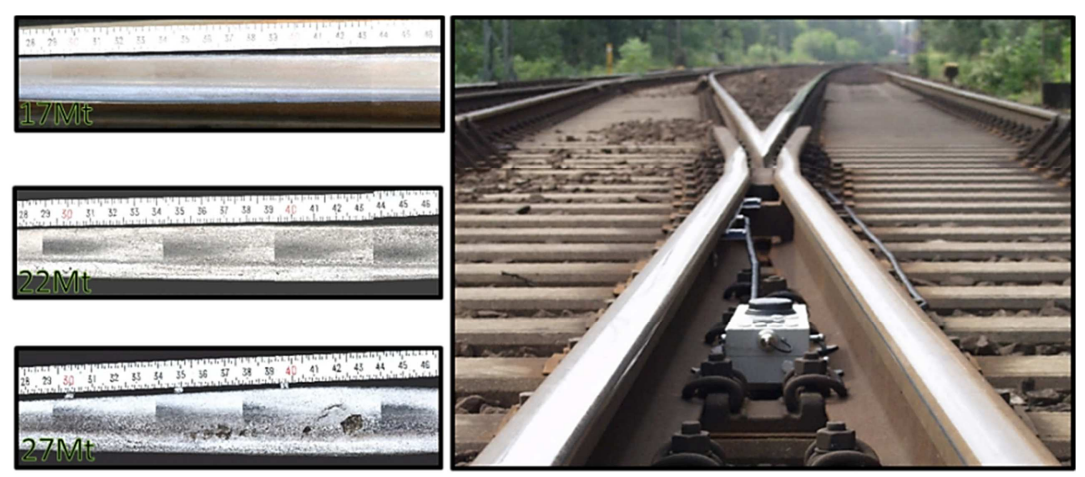

Fig. 1: The track-side inertial measurement systems: left - RCF development images and their times in megatons (Mt), right - ESAH-M [17]). 
The concept of PHM implicates the series of steps: data acquisition, data processing, detection, diagnostics, prognostics, and advisory generation [18]. The monitoring methods that are based on inertial measurements have significant advantage of simple and reliable data acquisition. However, the experience of their application for recent detection, diagnostics and especially prognostics of railway infrastructure, has shown significant problems. Different to the engineering problems, like rolling bearing of gear-box analysis, where the inertial monitoring is successfully used. The problem consists in difficulty of interpretation of the measurement results. The performance studies $[19,20]$ of the track-side inertial monitoring systems have shown the significant random variation of the measured accelerations that is much higher than the systematic changes during the crossing lifecycle. The accelerations in the new crossings are statistically compared not much differ to that from the end of the lifecycle. The reasons of the significant random variations are a lot of factors influencing the measurement results: different train types and their velocities, wheel profile wear, wheel trajectory change due to the lateral wheel position, etc. The error analysis of the system in the study [21] has recovered a potential error source due to unknown variation of the distance between the sensor and wheel impact position. It was experimentally shown, that the taking into account the effect of wave propagation, could significantly reduce the measurement uncertainty.

An application of modern signal processing and machine learning methods is a promising way for solving the problem of inertial measurement uncertainty. The methods allow exploiting the measurement information deeper and reveal the hidden relations. An overview of contemporary machine learning approaches with application to railway track infrastructure is presented in book [22]. A common crossing fault prediction with the track-side inertial measurements using non-linear signal processing techniques and regression methods is proposed in the study [23]. An assessment of the track condition from on-board acceleration measurements using the grey relational analysis method for is presented in [24]. The method determines the track condition using a similarity comparison between the obtained track profiles. On-board track condition monitoring with the machine learning approach is described in [25]. A learning system in the form of three independent neural networks is used within the approach to identify the track condition. Experimental studying the causes of a frog rail contact damages using track-side inertial and surface scanning measurements during the overall lifecycle is presented in [26]. Studies [27, 28] present a monitoring and prediction of quality development of track substructure for ballasted and ballastless track in transition areas. An analysis of ESAH-M measurements by statistical and mechanical approaches with the recovering the relation to the crossing lifetime is shown in [29]. Detection of track subgrade failures with on-board inertial measurements is studied in [30] based on scale modelling. A substantial improvement of common crossing inspection system using machine learning prognostics and track-side monitoring is proposed in [31]. The study [32] describes a method for rail squats and corrugation detection using bogie acceleration measurements on in-service trains. The method uses an analysis of the feature frequencies from the continuous wavelet analysis and the feature modes from the empirical mode decomposition. Track condition monitoring from in-service train's acceleration measurements is presented in [33]. A mathematical model and the frequency response analysis is used to process the information on track alignment and track irregularities.

A track quality indicator algorithm that is based on a modified Karhunen-Loève transformation, was developed in the study [34]. The algorithm is closely related to principal component analysis and extracts the principal dynamics from measurement data. A differential evolution technique based track measurement is presented in the paper [35], where the axle box measurements are considered. The new method enables to estimate the exact location of the irregularity. A development of condition indicator for on-board measurements, which is based on time and frequency domain features, with application of feature ranking and principal component analysis, is proposed in [36]. Monitoring of railway superstructure is shown in [37]. Rails displacement, temperatures, ballast pressure, stresses were measured and analyzed during the monitoring. Analysis of dynamic response on switches and crossings is demonstrated in [38].The dynamic response was numerically simulated by Finite Element Method model of common crossing. An analysis of the correlation between vehicle responses and track irregularities is presented in the study [39]. The analysis is bases on experimental measurements and modelling. The results show a high influence of track stiffness on the axle box acceleration. The data-driven prediction of the track degradation index using acceleration monitoring of in-service vehicles described in [40]. The three different machine learning models are presented: random forest regression, support vector machine with genetic algorithm and artificial neural network. The random forest regression model provided the best results of the prediction. 
Fractal analysis is a promising technique for signal analysis and feature extraction. It is used in [41] for track ballast and subgrade diagnostics and recovering the cause of track irregularities by quantifying the wavelength characteristics of the common track geometry data. An application of fractal analysis for the data driven assessment of railway superstructure and substructure degradation and the necessary predictive maintenance is considered in [42]. An analysis of the multi-fractal spectrum for estimation of railway fastenings condition was proposed in the study [43], where pulse stimulation measurement technique is used. An application of fractal geometry theory to describe the geometric evolution of rail weld irregularities is presented in [44].

The goal of this paper is the exploration of multifractal analysis to recover the hidden relations to the crossing lifetime in the inertial measurements of track-side ESAH-M system. The study is performed in the following steps: multifractal features extraction, significant features selection with Lasso (Least absolute shrinkage and selection operator) regularisation technique and feature fusion to one structural health indicator.

\section{The theoretical background of multi-fractal spectrum calculation}

The multifractal analysis, different to fractal one that is based on one parameter set of a fractal dimension, is based on the calculation of two sets of parameters related to the signals. The sets are Hölder exponent, and multifractal spectrum. Hölder exponent quantifies the local regularity of the signal and multifractal spectrum - its multifractality. The association of each of data group of the same regularity with the Hausdorff dimension by means of multifractal spectrum enables to define a function between the Hölder exponent and the Hausdorff dimension that is also known as singularity spectrum [45].

Nowadays there are a lot of computing methods for performing the fractal and multifractal analysis, like box-counting, fractional Brownian motion, spectral methods, etc. For the present study, spectral methods are used namely wavelet leader based multifractal analysis [46]. Wavelet leaders use the wavelet self-similarity structures in combination with the multiresolution analysis scheme. Wavelet leader's computation includes the search of the highest wavelet coefficient in a close time neighborhood, for all finer scales. It can be defined as follows [47]:

$L_{f}(j, k)=\sup _{\lambda^{\prime} \subset 3 \lambda}\left\{\left|d_{\lambda^{\prime}}\right|\right\}$

here, $d_{\lambda^{\prime}}$ - wavelet coefficients corresponding to the wavelet transform of the signal;

$3 \lambda=\left[\frac{k-1}{2^{j}}, \frac{k+2}{2^{j}}\right)-$ the dilated intervals, with scaling factor $\mathrm{M} \geq 3$.

The scaling function is computed based on the wavelet leaders:

$S_{W L}(q, j)=2^{-j} \sum_{k \in K_{j}} d_{j k}^{q}$,

here $q$ - order of scaling.

The scaling function decays as power laws of the scales if the signal has the self-similarity. The exponents of these power laws are called scaling exponents and are calculated as follows:

$\eta_{W L}(q)=\liminf \operatorname{si+\infty }_{j \rightarrow \infty} \frac{\log \left(S_{W L}(q, j)\right)}{2^{-j}}$.

The singularity spectrum is obtained from the scaling exponents with the help of a Legendre transform:

$D(h)=\inf _{q}\left(1+q h-\eta_{W L}(h)\right)$,

here $h$ - the Hölder exponent. 


\section{Preliminary analysis and multifractal features extraction}

A turnout with a stiff common crossing was monitored with track-side measurement system over the overall lifecycle $2 \mathrm{Mt}$. The geometrical parameters of the turnout are the angle 1/12, branch radius $500 \mathrm{~m}$. The common crossing is assembled from rails $60 \mathrm{E} 1$ of steel R350. The common crossing was monitored in 11 measurement actions. Each action included 5 - 6 train passages. Altogether 64 trains' passages with 2701 wheel axles were measured. Each measurement includes the impact position, train velocity and the spatial acceleration in the frog nose. The deep RCF damages appeared after $27 \mathrm{Mt}$ and after $29 \mathrm{Mt}$ the crossing was renewed. The variation of maximal vertical accelerations and the variation of the impact longitudinal position depending on the lifetime of the common crossing is shown on the Fig. 2.
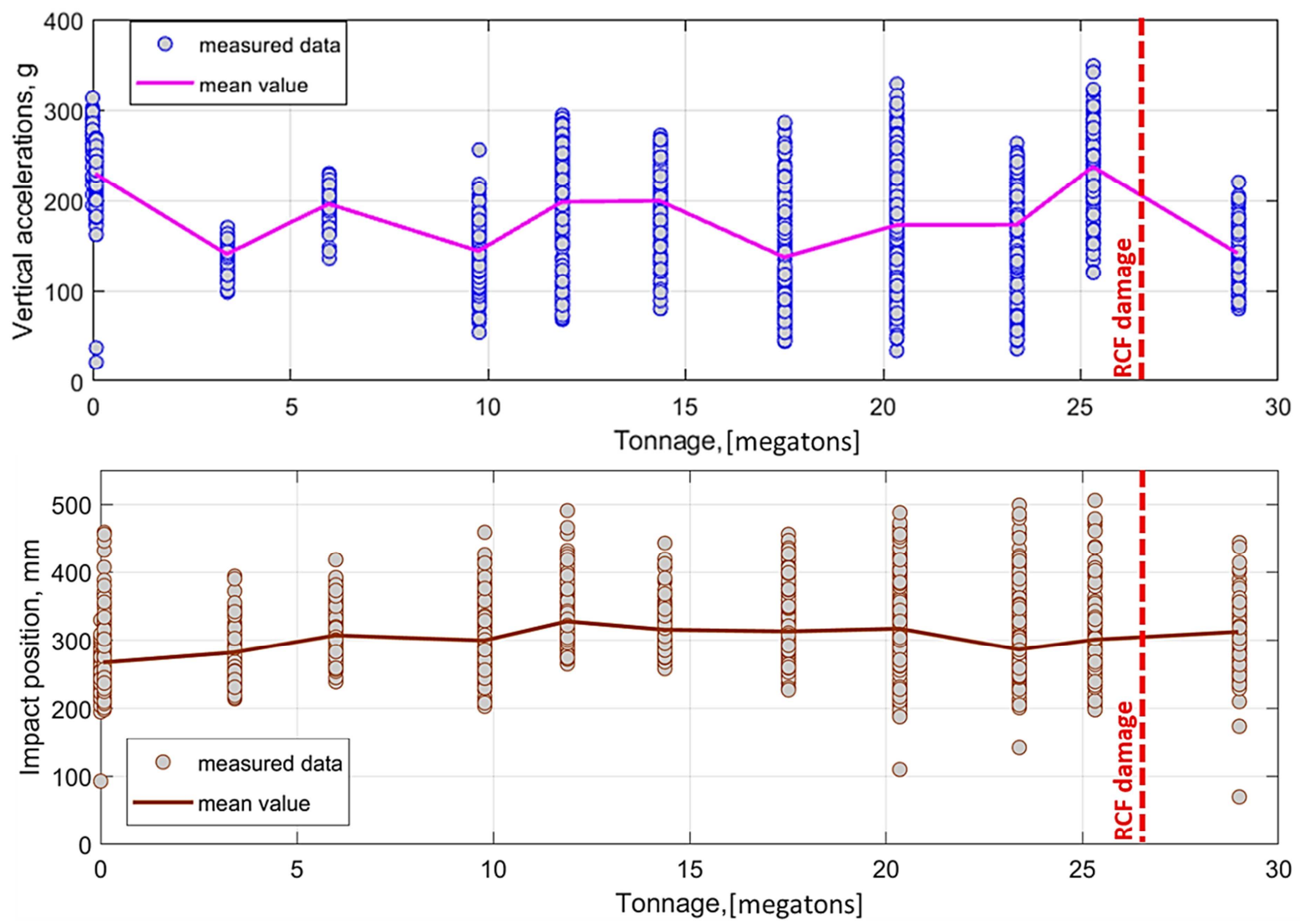

Fig. 2: The measured maximal vertical accelerations (top) and impact longitudinal position (bottom) in common crossing over its lifecycle.

Both the plots of acceleration and the plot of impact position show a high random variation of the parameters that is about as high as the mean measured values. A low systematic variation of the mean values along the lifetime can be observed on the impact position plot. The maximal vertical accelerations seem to be independent to the lifetime and therefore useless for crossing diagnostics.

A preliminary multifractal analysis was carried out to find out the differences between the new and old state of the common crossing. To exclude the external factors influence two acceleration measurements were selected with the same rolling stock and about the same velocity. The only significant difference was the time of measurements: near to begin and close to end of the crossing lifecycle. The measurements are shown on the Fig. 3. 

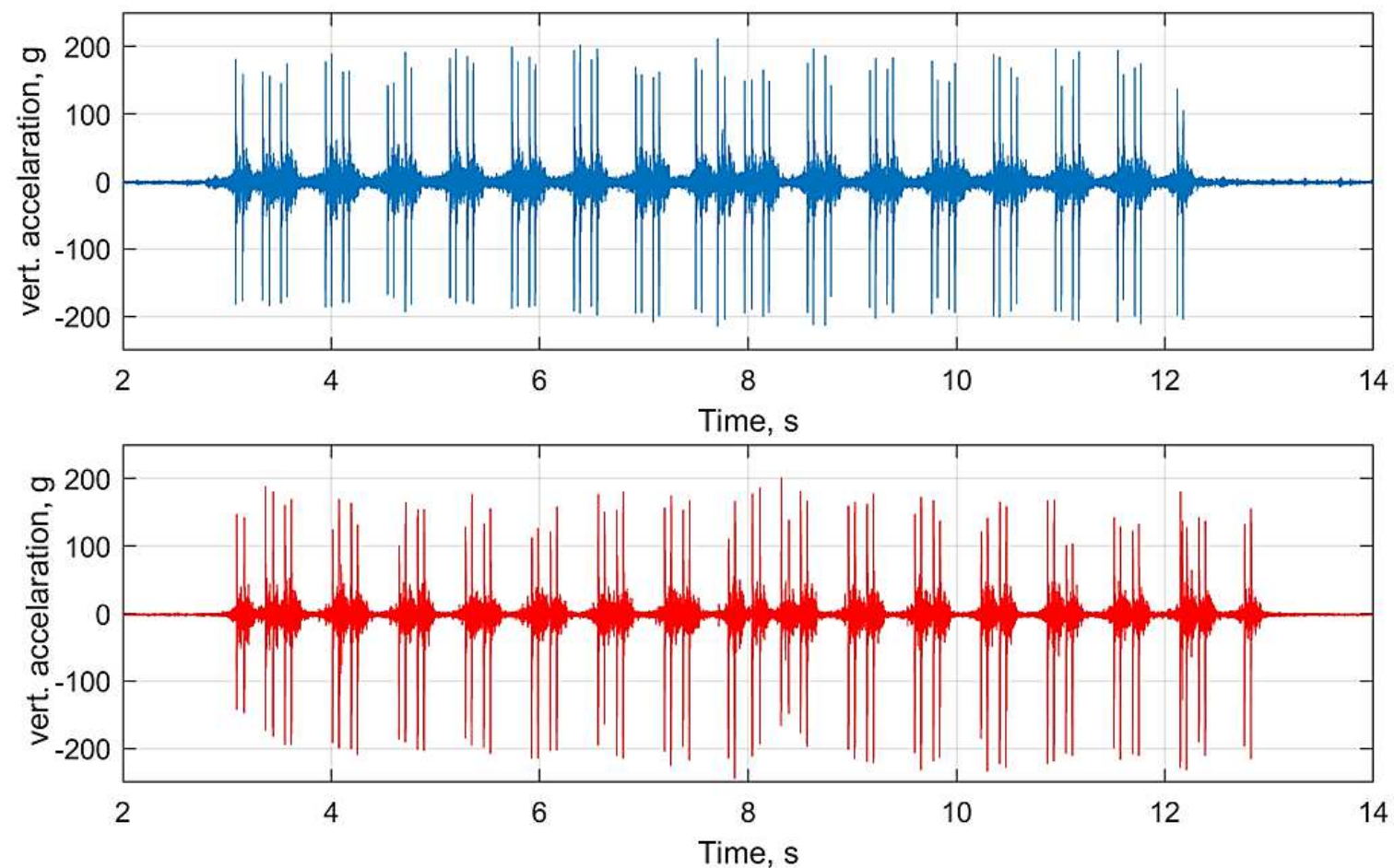

Fig. 3: The measured vertical accelerations on the web of common crossing frog-rail for the train ICE with speed $160 \mathrm{~km} / \mathrm{h}$, at the begin (top plot) and the end (bottom plot) of the lifecycle.

The Fig. 3 of the measured acceleration demonstrates that there is almost the same acceleration width $\pm 200 \mathrm{~g}$ for these two cases. Therefore, the maximal accelerations cannot be considered as good condition indicator for common crossings. To recover the difference between the measurements, multifractal analysis was carried out. Fig. 4 depicts the results in form of two parameter sets: the singularity exponent and singularity spectrum. Both parameters show significant differences between the measurements. Thus, the multifractal parameters can be used as features for the development of condition indicator for common crossings.
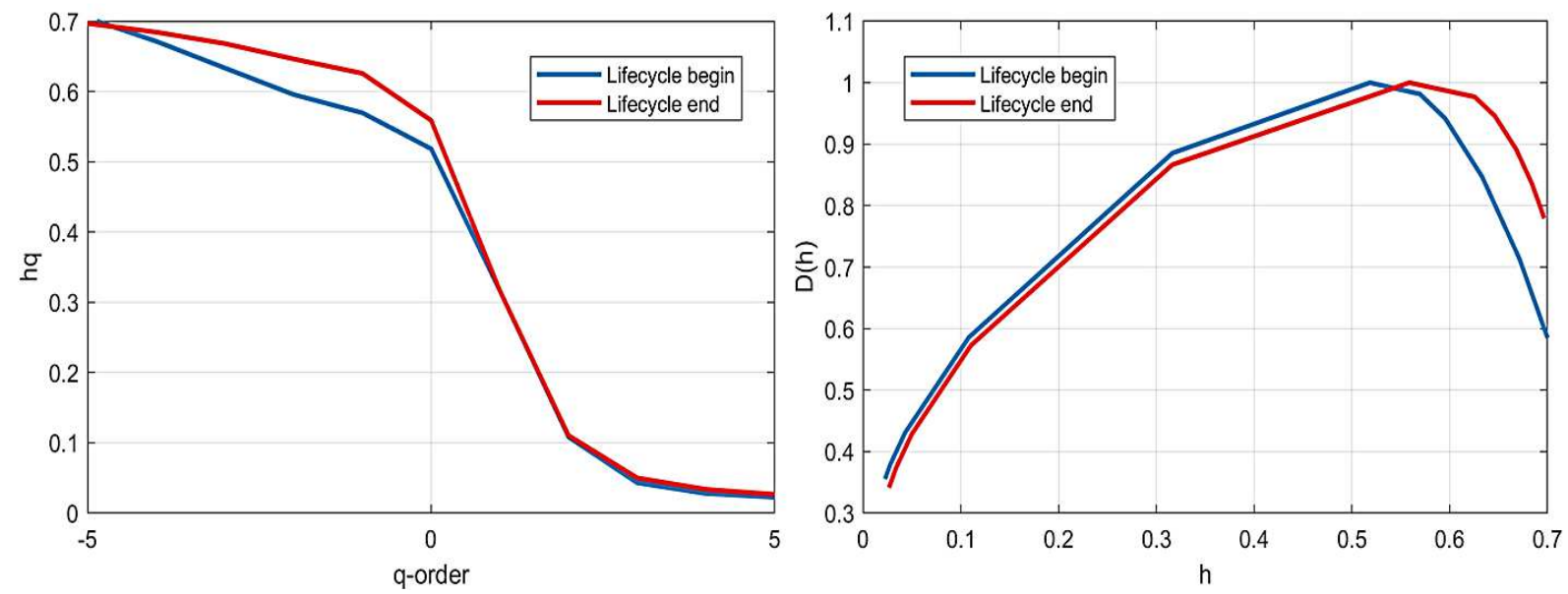

Fig. 4: The singularity exponent (left) and the singularity spectrum (right) for the lifecycle begin and end.

For each acceleration component, 15 features were extracted: singularity spectrum or the range of Holder exponents, three cumulants of the scaling exponents and 11 Holder exponent points for the $q$-order from -5 to 5 . Also, two operation conditions are added to the feature set: the train speed and the impact longitudinal position on the frog nose of common crossing. Altogether 47 features are included to one observation. 
Table 1: Feature set for one observation.

\begin{tabular}{|c|c|}
\hline Abbr. & Description \\
\hline meanV & train velocity \\
\hline$m A u f s P o s$ & impact longitudinal position on the frog nose \\
\hline$c p X 1 \ldots c p X 3$ & cumulants of the scaling exponents for the lateral acceleration \\
\hline$c p Y 1 \ldots c p Y 3$ & cumulants of the scaling exponents for the vertical acceleration \\
\hline$c p Z 1 \ldots c p Z 3$ & cumulants of the scaling exponents for the longitudinal acceleration \\
\hline$r h X, r h Y, r h Z$ & singularity spectrum for the acceleration components \\
\hline$h X 1 \ldots h X 11$ & Holder exponents for the lateral acceleration \\
\hline$h Y 1 \ldots h Y 11$ & Holder exponents for the vertical acceleration \\
\hline$h Z 1 \ldots h Z 11$ & Holder exponents for the longitudinal acceleration \\
\hline
\end{tabular}

To extract more observations from 65 train's passages, the time-series of accelerations are analyzed in the windows 10000 points wide, that comprise at least 2 wheel axles passage. This enables to extract 473 observations for the overall lifecycle. A correlation matrix diagram is constructed (Fig. 5) for the preliminary analysis of features influences. The diagram graphically depicts in the form of matrix the pairwise correlations between all features including the tonnage. Remarkable in the diagram is the high collinearity of the first left 5 Holder exponents in for one component of acceleration and between the acceleration components. The most interesting is the relation of the features to the lifetime that is depicted by the left column or the top row of the matrix. The highest correlation to the lifetime of crossing has the following features: $r h X 1, h X 1-3, h X 7, r h Y 1, h Y 1-3, h Z 1$, $h Z 2$. However, the correlation is relative week and do not exceed 0.25 .

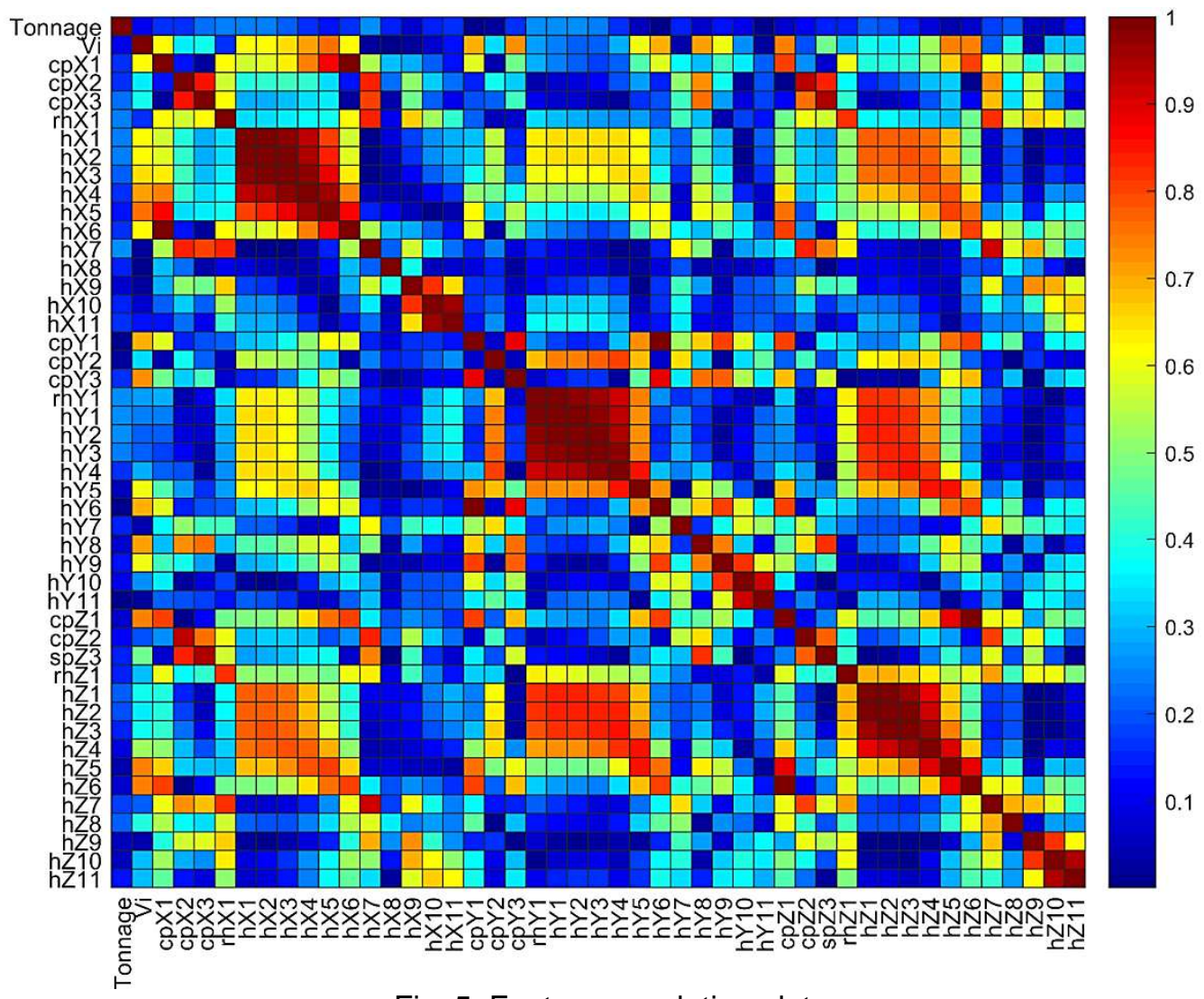

Fig. 5: Feature correlation plot.

To explore the time relations of the most correlated features, the plot of normalized and cantered feature values depending on the lifetime (Fig. 6). The lifetime is presented in measurement point or wheel axle and the feature values are averaged to each train. Additionally, the train speeds feature is shown.

Fig. 6 explains the reason of higher correlation for the feature $h X 7$ than for the other features: two outliers in the statistic influence the correlation coefficient more than all the feature data. 
Therefore, only the correlation to the lifetime is a necessary but not the sufficient condition for the feature suitability as a condition indicator.

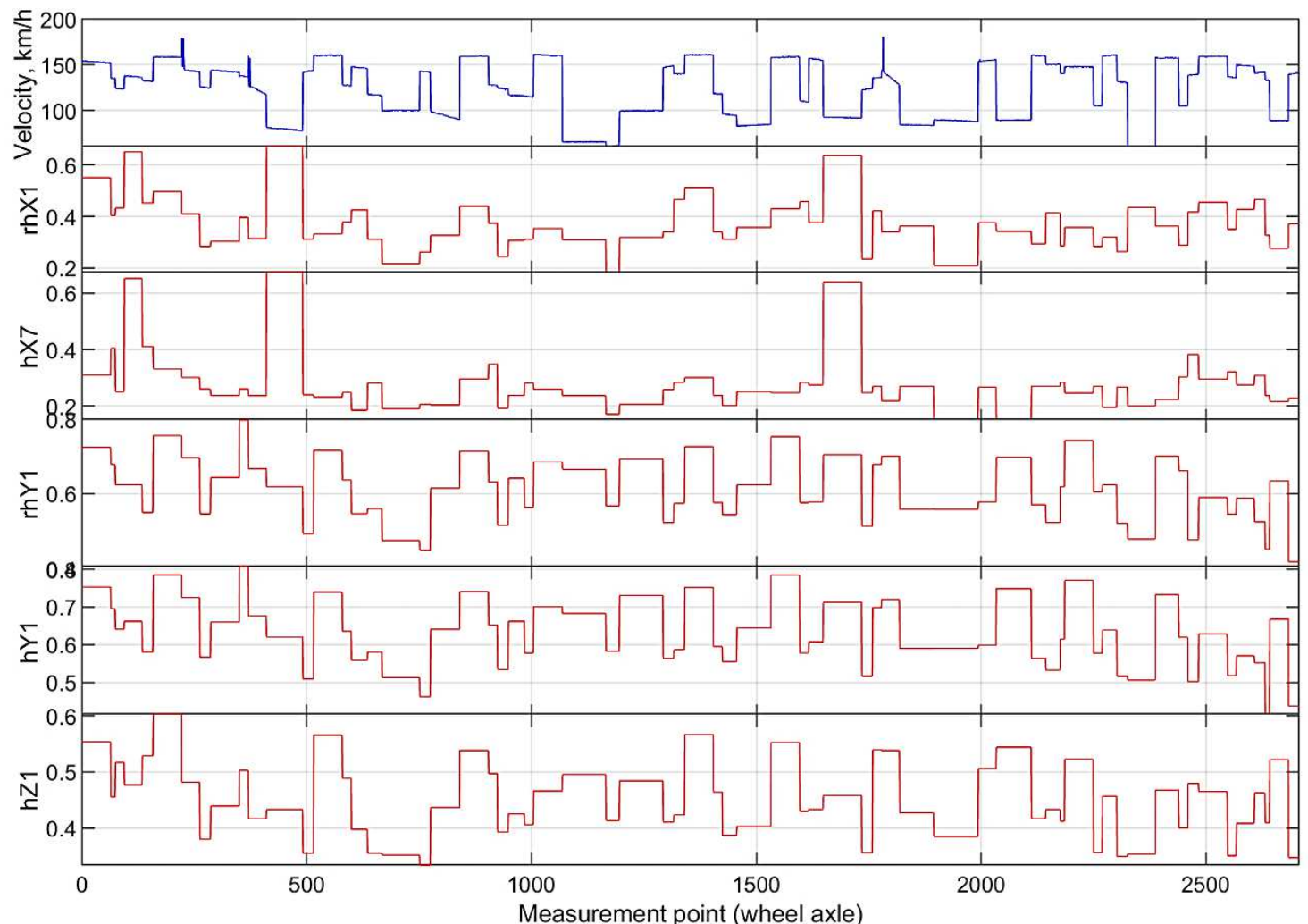

Fig. 6: The process of the most correlated features, averaged to the wheel axles.

\section{Features selection with Lasso regularisation}

There are altogether 47 features that contain some relation to the crossings lifetime but also the noise. A features selection process is necessary for selecting a subset of the relevant features, reduction of the overfitting or variance, and simplification for further model development. The present study is directed on the development of the simple monitoring method and intuitive clear condition indicator. The modern machine and deep learning methods offer a lot of high efficient nonlinear and black-box techniques for the present problem. However, the complicated models, together with good learning results, bring also the problem of interpretation [48]. Clear relation between a predictor and the response is one of the prerequisites to the methods for the practical industrial application [49]. The linear regression models are most suitable for the purposes.

Linear regressions with Lasso regularisation are used for the lifetime prediction of the common crossing. A multiple linear regression model is defined as follows:

$\hat{y}_{i}=b_{1} x_{i 1}+b_{2} x_{i 2}+\cdots+b_{p} x_{i p}$,

where $\hat{y}_{i}$-estimated response; $b_{p}$ - the fitted coefficients for $p$-predictor or feature, $x_{i}$ - the features of $i$-observation.

The Lasso regularization technique is used to identify important among the redundant predictors and therefore to receive lower prediction errors. The optimal $b_{p}$ coefficients are found by the solution of the following problem:

$\min _{b_{0}, b}\left(\frac{1}{2 N} \sum_{i=1}^{N}\left(y_{i}-b_{0}-x_{i} b\right)^{2}+\lambda \sum_{j=1}^{p}\left|b_{j}\right|\right)$

where, $\lambda$ - a positive regularization parameter; $N$ - the number of observations.

The variation of regularization coefficient $\lambda$ in the formula (6) causes the corresponding variation of the fitting mean square error (MSE) that is shown on the Fig. 7. The lowest MSE is where the 
$\lambda_{\text {minMSE }}$ is about 0.01 . The number of features are different for the various $\lambda$ : the low $\lambda$ corresponds to more features considered and vice versa.

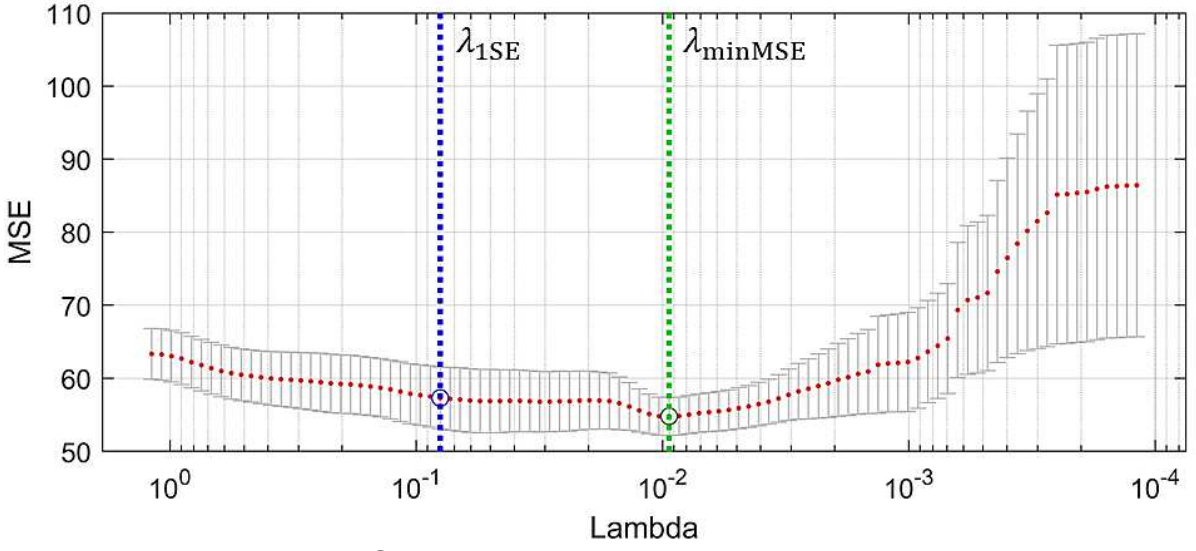

Fig. 7: MSE depending on shrinkage parameter.

It is clear from the Fig. 7, that the regression model with all features considered has a high MSE. The model is usually more parsimonious with less parameters. Therefore, in addition to the optimal solution also the suboptimal one is introduced - the $\lambda_{1 \text { SE }}$ that is the largest lambda value such that deviance is within one standard error of the minimum.

The Lasso method application comprises not only the minimum error search for the coefficient in $\lambda$, but also the cross-validation of the results to assure the model validation. The uncertainty bounds of the MSE estimation (Fig. 7) correspond to the solutions for the 10-fold cross-validation.

Fig. 8 demonstrates the dependence of coefficients fit by Lasso on the regularization coefficient $\lambda$ and the number of selected features. The selected features for the optimal $\lambda$ are depicted as thick lines. Thus, the optimal feature set consists of 35 features and the suboptimal set within one standard error has 23 features.

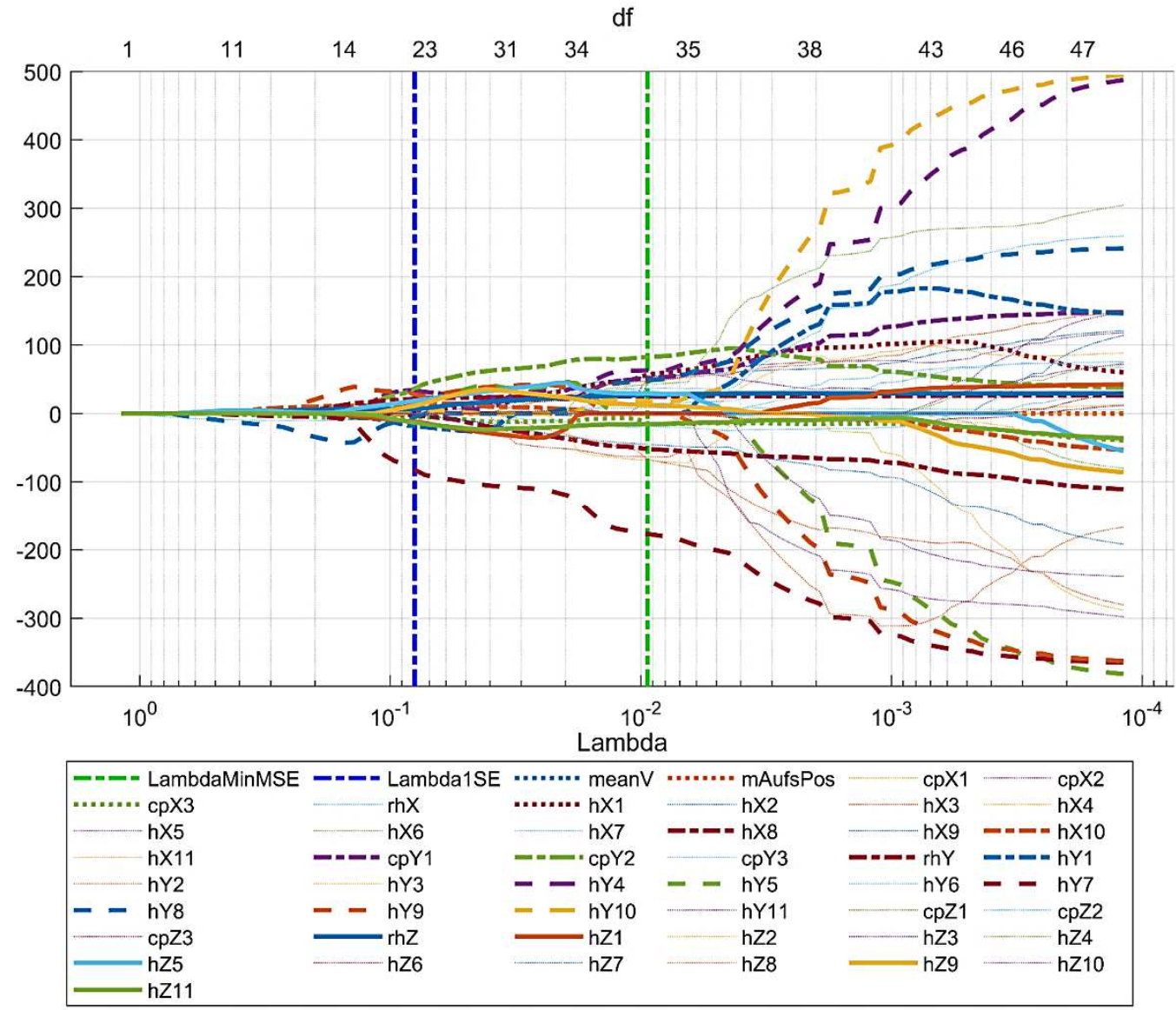

Fig. 8: Lasso regularisation plot and the optimal number of features. 
The results of feature fusion to one condition indicator $(\mathrm{Cl})$ for the both datasets, as well as the feature ranking, are shown on the Fig. 9 and 10. Both regression plots, contrary to the plots of maximal vertical accelerations and impact position (Fig. 2), prove the evident relation to the lifetime of the common crossing. The regression line for the optimal solution with 35 features (Fig. 9) has the systematic variation within 7 levels of $\mathrm{Cl}$ with $95 \%$ indeed lower coefficient of determination $22 \%$ but also significantly lower normalized root-mean-square deviation. The most important feature is the $h Y 7$ that had not the best correlation on the correlation plot (Fig. 5), but can be clearly explained from the singularity exponent plot (Fig. 4, left). Remarkable is the component of acceleration: almost all significant features are extracted from the vertical accelerations for the solution with the 23 features. The minor influence has the longitudinal accelerations with features $h Z 1$ and $h Z 5$. The lateral accelerations play almost no role. The feature of operational condition mean $V$ that corresponds to train speed plays also an important role in the statistics, whereas the influence of the impact longitudinal position feature mAufsPos is almost negligible.
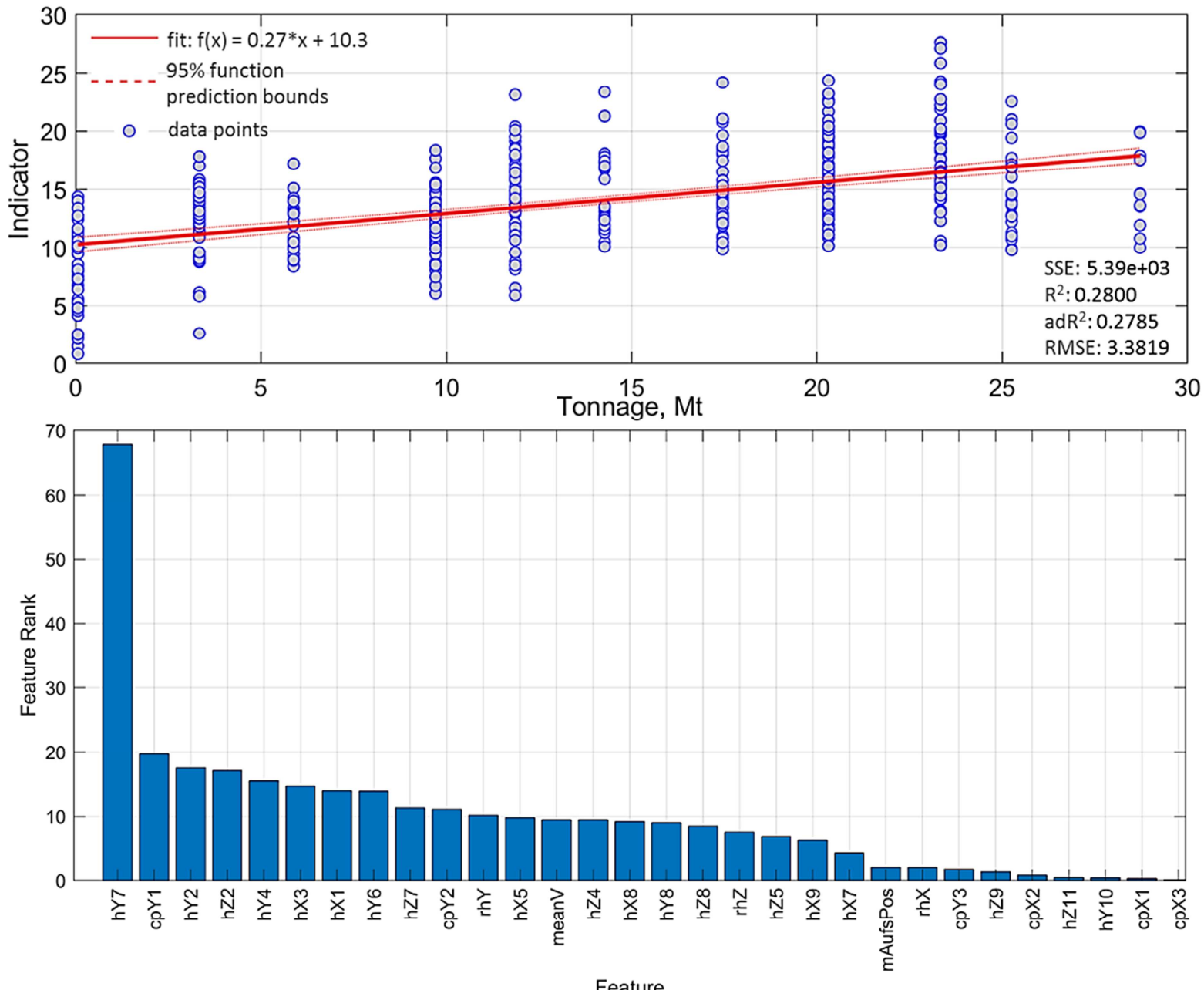

Fig. 9: Linear regression of the condition indicator for the 35 selected features (top) and the feature importance ranking (bottom). 

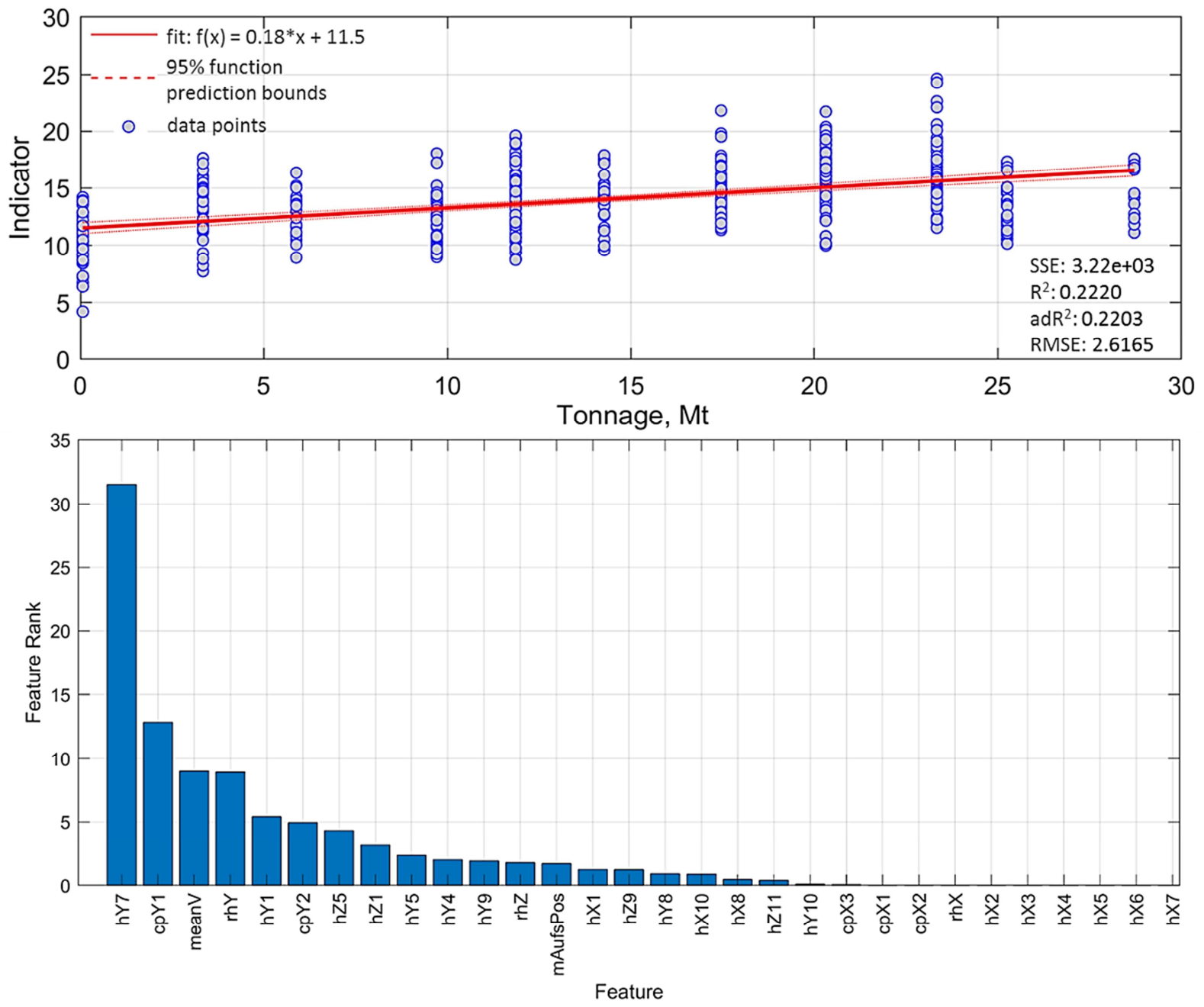

Fig. 10: Linear regression of the condition indicator for the 23 selected features (top) and the feature importance ranking (bottom).

\section{Conclusions}

The present paper has explored the potentials of applying the multifractal analysis for monitoring and diagnosis of common crossings. The multifractal analysis reveals the hidden relations to the lifetime in the crossing loading condition that are not possible to estimate with the analysis of maximal accelerations. The correlation test of the extracted 47 features from the acceleration components has shown the relation of many features to the lifetime of crossing, but also a high correlation between the features. This indicated on the feature collinearity and the redundancy of the extracted information. The applied Lasso regularization technique for the linear regression allowed selecting the best features and removing the redundant ones. The best fitting results are reached with 35 features regression. The regression with 23 features provides somewhat lower coefficient of determination, but also significantly lower random deviation of the results. The selected features are mostly dependent on the vertical accelerations that rises a question of necessity of the lateral and longitudinal accelerations. The feature ranking analysis shows the importance of the information about the operational conditions namely the train velocity. This means that only measurement of the accelerations would provide much worse diagnostic results.

Despite of relatively good results of applying the multifractal analysis for the common crossing condition estimation, it should be noted that the practical application would require the further improvements. The wide-ranging scatter of the developed indicator can cause the low prediction quality for low number of observations. The fusion of fractal features with time and frequency-domain features with other analysis would be a plausible way for the future research. 


\section{References}

[1] http://europa.eu/rapid/press-release_IP-11-372_en.htm

[2] https://www.osce.org/secretariat/101047?download=true

[3] FENDRICH, L. - FENGLER, W.: Handbuch Eisenbahninfrastruktur (Field manualRailway Infrastructure). Springer-Verlag Berlin Heidelberg, 2013. doi.org/10.1007/978-3-642-30021-9.

[4] LETOT, C., et al.: A Data Driven Degradation-based Model for the Maintenance of Turnouts: A Case Study, IFACPapersOnLine, Vol. 48, 2015, pp. 958-963, doi.org/10.1016/j.ifacol.2015.09.650.

[5] GERBER, U. - ZOLL, A. - FENGLER, W.: Verschleiß und Fahrflächenermüdung an Weichenmit starrer Herzstückspitze (Wear and Rolling Contact Fatigue on common crossings of railway turnouts). ETR - Eisenbahntechnische Rundschau, No. 1, 2015, pp. 36-41.

[6] INNOTRACK - Innovative Track Systems. Deliverable D3.1.1/D3.1.2, Definition of Key Parameters and Report on Cost Drivers for Goal-directed Innovation, 37 p., 2008.

[7] XIN, L.: Long-Term Behaviour of Railway Crossings: Wheel-Rail Interaction and Rail Fatigue Life Prediction. PhD. Thesis, TU Delft, 2017, 218 p. DOI: 10.4233/uuid:7ee5405a-85f1-4bd2-b776$2013715 c 8783$.

[8] MAHBOOB, Q. - ZIO, E.: Handbook of RAMS in Railway Systems: Theory and Practice. CRC Press, 2018, 765 p., https://doi.org/10.1201/b21983.

[9] BRAJOVIC, L. M. - MALOVIC, M. - POPOVIC, Z. - LAZAREVIC, L.: Wireless System for Sleeper Vibrations Measurement. Communications - Scientific Letters of the University of Zilina, Vol. 16 (4), 2014, pp. 21-26.

[10]BÖHM, T. - WEISS, N.: Turnout Analytics - Smart Sensors and Artificial Intelligence for the Allround Healthy Turnout (in German). Eisenbahntechnische Rundschau, No. 5, 2017, pp. 42-45.

[11] AKKERMAN, G. L. - SKUTINA, M. A.: Balisa as a Way to Control Stress State of Rail Bars, Track Distortion and Break (in Russian). Innovative transport, Vol. 3 (17), 2015, pp. 34-38.

[12] KHAIRALLAH, D. - BLANC, J. - COTTINEAU, L.M. - HORNYCH, P. - PIAU, J. - POUGET, S. HOSSEINGHOLIAN, M. - DUCREAU, A. - SAVIN, F.: Monitoring of Railway Structures of the High Speed Line BPL with Bituminous and Granular Sublayers. Construction and Building Materials, Vol. 211, 2019, pp. 337-348, DOI: 10.1016/j.conbuildmat.2019.03.084.

[13] HE, M. - FENG, L. - ZHAO, D.: Application of Distributed Acoustic Sensor Technology in Train Running Condition Monitoring of the Heavy-haul Railway. Optik, Vol. 181, 2019, pp. 343-350, DOI: 10.1016/j.ijleo.2018.12.074.

[14] CAÑETE, E. - CHEN, J. - DÍAZ, M. - LLOPIS, L. - RUBIO, B.: Wireless Sensor Networks and Structural Health Monitoring: Experiences with Slab Track Infrastructures. International Journal of Distributed Sensor Networks, Vol. 15, No. 3, 2019, DOI: 10.1177/1550147719826002.

[15] TASTIMUR, C. - KARAKOSE, M. - AKIN, E. A.: Vision Based Condition Monitoring Approach for Rail Switch and Level Crossing using Hierarchical SVM in Railways. IJAMEC, 4 (Special Issue), 2016, pp. 319-325.

[16]DHAR, S. - ZHANG, Y. - XU, R. - DANIELSEN, H. K. - JUUL JENSEN, D.: Synchrotron X-ray Measurement of Residual Strain within the Nose of a Worn Manganese Steel Railway Crossing. IOP Conference Series: Materials Science and Engineering, Vol. 219 (1), 2017.

[17]ZOLL, A. - GERBER, U. - FENGLER, W.: Das Messsystem ESAH-M (The Measuringsystem ESAH-M). El-Eisenbahningenieur Kalender, 2016, pp. 49-62, ISSN:0934-5930.

[18] IEC. IEC TR 62278-3: 2010: Railway Applications-Railway Applications-Specification and Demonstration of Reliability, Availability, Maintainability and Safety (RAMS) - Part 3: Guide to the Application of IEC 62278 for Rolling Stock RAM. Geneva: IEC, 2010.

[19] LIU, X. - MARKIENE, V. L. - SHEVTSOV, I. Y.: Experiment Study of Key Parameters in Turnout Crossing Degradation Process. Proceedings of the $10^{\text {th }}$ International Conference on Contact Mechanics (CM2015). AAR, Sept. 1-3, 2015, Colorado (USA).

[20] GERBER, U. - FENGLER, W.: Belastung von Weichen mit starrer Herzstückspitze [Load of Turnouts with a Rigid Frog]. ZEVrail Glaser Annalen, Vol. 131 (5), 2007, pp. 202-214.

[21]SYSYN, M. P. - KOVALCHUK, V. V. - JIANG, D.: Performance Study of the Inertial Monitoring Method for Railway Turnouts. International Journal of Rail Transportation, 7:2, 2019, p. 103-116. DOI: $10.1080 / 23248378.2018 .1514282$.

[22] ATTOH-OKINE, N.: Big Data and Differential Privacy: Analysis Strategies for Railway Track Engineering. John Wiley \& Sons, Inc., 2017. DOI: 10.1002/ 9781119229070.

[23]SYSYN, M. et al.: Common Crossing Structural Health Analysis with Track-side Monitoring. Communications - Scientific Letters of the University of Zilina, 21, (3), 2019, pp. 77-84.

[24]TABASZEWSKI, M. - FIRLIK, B.: Assessment of the Track Condition Using the Gray Relational Analysis Method. Eksploatacja i Niezawodnosc, Vol. 20 (1), 2018, pp. 147-152, DOI: 10.17531/ein.2018.1.19. 
[25]FIRLIK, B. - TABASZEWSKI, M.: Monitoring of the Technical Condition of Tracks Based on Machine Learning. Proceedings of the Institution of Mechanical Engineers, Part F: Journal of Rail and Rapid Transit, 2019, at Press. DOI: 10.1177/0954409719866368.

[26] SYSYN, M. et al.: Experimental analysis of rail contact fatigue damage on frog rail of fixed common crossing 1:12 [online]. Journal of Failure Analysis and Prevention, Vol. 19 (4), 2019, pp. 1077-1092, DOI: 10.1007/s11668-019-00696-w.

[27] IZVOLT, L. - SESTAKOVA, J. - SMALO, M.: Analysis of Results of Monitoring and Prediction of Quality Development of Ballasted and Ballastless Track Superstructure and its Transition Areas. Communications - Scientific Letters of the University of Zilina, Vol.18 (4), 2016, pp. 19-29.

[28] IZVOLT, L. - SESTAKOVA, J. - SMALO, M.: The Railway Superstructure Monitoring in Bratislava Tunnel No. 1 - Section of Ballastless Track and its Transition Areas. MATEC Web of Conferences, Vol. 117, 2017, 00063.

[29] SYSYN, M. et al.: Common Crossing Fault Prediction with Track Based Inertial Measurements: Statistical vs. Mechanical Approach. Pollack Periodica [online], Vol. 14 (2), 2019, pp.15-26, DOI: 10.1556/606.2019.14.2.2.

[30]RAPP, S. et al.: Track - vehicle Scale Model for Evaluating Local Track Defects Detection Methods. Transportation Geotechnics, Vol. 19, 2019, pp. 9-18, doi: 10.1016/j.jrtpm.2016.03.001.

[31] SYSYN, M. et al.: Improvement of Inspection System for Common Crossings by Track Side Monitoring and Prognostics. Structural Monitoring and Maintenance, Vol. 6 (3), 2019, p. 219-235, DOI: 10.12989/smm.2019.6.3.219.

[32]WEI, X. et al.: Squats and Corrugation Detection of Railway Track Based on Time-Frequency Analysis by Using Bogie Acceleration Measurements. Vehicle System Dynamics, 2019, at Press. DOI: 10.1080/00423114.2019.1610181.

[33] WEI, X. et al.: Urban Rail Track Condition Monitoring Based on In-Service Vehicle Acceleration Measurements. Measurement: Journal of the International Measurement Confederation, Vol. 80, 2016, p. 217-228, DOI: 10.1016/j.measurement.2015.11.033.

[34] CHUDZIKIEWICZ, A. - KOSTRZEWSKI, M. - KONOWROCKI, R.: Condition Monitoring of Railway Track Systems by Using Acceleration Signals on Wheelset Axle-Boxes. Transport, Vol. 33 (2), 2018, pp. 555-566, DOI: 10.3846/16484142.2017.1342101.

[35] CHELLASWAMY, C. - MUTHAMMAL, R. - GEETHA, T. S.: A new Methodology for Optimal Rail Track Condition Measurement Using Acceleration Signals. Measurement Science and Technology, Vol. 29 (7), 2018, 075901, DOI: 10.1088/1361-6501/aabe48.

[36] SYSYN, M. et al.: Common crossing condition monitoring with on-board inertial measurements. Acta Polytechnica, Vol. 59 (4), 2019, pp. 423-434, DOI: 10.14311/AP.2019.59.0423.

[37] PLASEK, O. - SVABENSKY, O. - VALENTA, M.: Monitoring of Interaction between Railway Superstructure and Bridge. Civil-Comp Proceedings, 2012, 98, DOI: 10.4203/ccp.98.49.

[38] SALAJKA, V. et al.: Numerical Analysis of Dynamic Response in Railway Switches and Crossings. Applied System Innovation - Proceedings of the International Conference on Applied System Innovation, ICASI 2015, 2016, pp. 1163-1168.

[39]KARIS, T. - BERG, M. - STICHEL, S.: Analysing the Correlation Between Vehicle Responses and Track Irregularities Using Dynamic Simulations and Measurements. Proceedings of the Institution of Mechanical Engineers, Part F: Journal of Rail and Rapid Transit, 2019, at Press. DOI: $10.1177 / 0954409719840450$.

[40]FALAMARZI, A. - MORIDPOUR, S. - NAZEM, M.: Development of a Tram Track Degradation Prediction Model Based on the Acceleration Data. Structure and Infrastructure Engineering, Vol. 15 (10), 2019, pp. 1308-1318, DOI: 10.1080/15732479.2019.1615963.

[41] LANDGRAF, M. - HANSMANN, F.: Fractal Analysis as an Innovative Approach for Evaluating the Condition of Railway Tracks. Proceedings of the Institution of Mechanical Engineers, Part F: Journal of Rail and Rapid Transit, 2018, DOI: 10.1177/0954409718795763.

[42] HOELZL, C. - CHATZI, E. - WINKLEHNER, D.: Data-driven Assessment of Railway Infrastructure, Master Thesis, Institute of Structural Engineering, 2019, ETH Zurich, Zurich.

[43]ZHANG, H. - LIU, Q.: Study On Rail Fastener Failure Testing Based on Fractal Theory, Vibroengineering Procedia, Vol. 14, 2017, pp. 208-213, DOI: 10.21595/vp.2017.19171.

[44]GAO, Y. - WANG, P. - XU, J. - CHEN, R.: Influence of Weld Irregularity on Wheel-rail Dynamic Interaction of Heavy Haul Railway. Huazhong Keji Daxue Xuebao (Ziran Kexue Ban)/Journal of Huazhong University of Science and Technology (Natural Science Edition), Vol. 46 (1), 2018, pp. 98-103, DOI: 10.13245/j.hust.180119

[45]SALAT, H. - MURCIO, R. - ARCAUTE, E.: Multifractal Methodology. Physica A: Statistical Mechanics and its Applications, Vol. 473, 2017, pp. 467-487, DOI: 10.1016/j.physa.2017.01.041. 
[46] SERRANO, E. - FIGLIOLA, A.: Wavelet Leaders: A new Method to Estimate the Multifractal Singularity Spectra. Physica A: Statistical Mechanics and its Applications, Vol. 388 (14), 2009, pp. 2793-2805, DOI: 10.1016/j.physa.2009.03.043.

[47] LEONARDUZZI, R. F. - SCHLOTTHAUER, G. - TORRES, M. E.: Wavelet Leader Based Multifractal Analysis of Heart Rate Variability During Myocardial Ischemia. 2010 Annual International Conference of the IEEE Engineering in Medicine and Biology Society, EMBC'10, 5626091, 2010, pp. 110-113.

[48] HASTIE, T. - TIBSHIRANI, R. - FREIDMAN, J.: The Elements of Statistical Learning: Data Mining, Inference, and Prediction. $2^{\text {nd }}$ ed. Springer-Verlag New York, 2009, 745 p. DOI: 10.1007/978-0387-84858-7.

[49]BEUTLER, A. - SIMROTH A.: Prädictive Instandhaltungsplannung [Predictive Planning of Maintenance]. Eisenbahn Ingenieur, Vol. 09, 2018, pp. 90-93. 